\title{
Pain and satisfaction during rigid cystoscopic ureteral stent removal: a preliminary study
}

\author{
Jae Heon Kim', Sun Young Park ${ }^{2}$, Mun Gyu Kim², Hoon Choi ${ }^{3}$, Dan Song ${ }^{4}$, Sung Woo Cho ${ }^{4}$ and Yun Seob Song ${ }^{\text {* }}$
}

\begin{abstract}
Background: Cystoscopy evokes discomfort and pain, especially in males. The cystoscopic retrograde approach is standard in the removal of ureteral stents. However the satisfaction and degree of pain during the procedure according to the use of several pain controlling methods are unclear.

Methods: This is a cross-sectional survey of 60 patients who underwent cystoscopic ureteral stent removal under intravenous analgesics (group 1, $\mathrm{n}=20$ ), midazolam induction (group 2, $\mathrm{n}=20$ ), and propofol (group 3, $\mathrm{n}=20$ ). Procedural pain and post-procedure satisfaction were determined, and cost differences between the approaches were clarified.

Results: Group 2 and 3 showed significantly less pain than group $1(P<0.001)$ and significantly higher satisfaction rate than group $1(P<0.001)$. Comparison of groups 2 and 3 revealed showed significantly less pain and higher satisfaction rate in group 3 ( $\mathrm{P}<0.001$ for both). In Group 1, 17 (85.0\%) patients wanted other treatment modalities, compared to eight group 2 patients (40.0\%) and no group 3 patients.

Conclusions: Considering the potential pain and dissatisfaction of rigid cystoscopic ureteral stent removal, procedures utilizing moderate sedation with midazolam or general anesthesia using propofol without muscle relaxation should be considered.

Trial registration: KCT0001260.

Keywords: Stent, Stent exchange, Stent removal, Cystscopy, Urolithiasis, Pain
\end{abstract}

\section{Background}

Although the real benefit of ureteral stenting after ureteroscopic removal of stone (URS) is contentious, the chance with ureteral stenting following ureteroscopic removal of stone is frequent [1]. After URS, ureteral stents are removed at post-operative 1 or 2 weeks, typically by cystoscopic retrograde removal [2,3]. However, because of the rigidity and larger diameter of cystoscopes, most patients need analgesia and some patients need deep sedation during the procedure [2,3]. In real practice, those stents are removed mostly in the outpatient setting using urethral lubrication jelly with or without narcotic intramuscular premedication [4-6].

Recently, lubrication jelly and lidocaine injection were reported to be no more effective for pain control during

\footnotetext{
*Correspondence: yssong@schmc.ac.kr

'Department of Urology, Soonchunhyang University Hospital, 657

Hannam-Dong, Yongsan-Gu, Seoul 140-743, Korea

Full list of author information is available at the end of the article
}

cystoscopy [7-11]. A flexible cystoscopy is a good alternative to rigid cystoscopy to reduce pain during procedure, but flexible cystoscopy is less available in korea and moreover there have been little reports about ureteral stent removal with flexible cystoscopy.

There have been many studies about pain during rigid or flexible cystoscopy, but there have been few studies about pain during cystoscopic stent removal. Although shorter in duration than cystoscopy, cystoscopic stent removal yields a similar pain to cystoscopy, and moreover larger diameter of rigid cystoscopy is needed for use of foreign body forceps. In our previous pilot study, cystoscopy using midazolam produced marginally greater satisfaction among men [6]. This is the main reason why we adapted diverse pain controlling method including propofol. The aim of this prospective, randomized, pilot study was to compare the satisfaction about cystoscopic stent removal according to different pain relief methods and to compare the costs. 


\section{Methods}

\section{Study sample}

From September 2012 to March 2013, 60 male patients with a history of prior URS and ureteral stenting due to ureteral stone were enrolled. Informed consent was obtained from all patients. The mean age of patients was 47.45 years. Subjects with severe cardiovascular disease, pulmonary disease, liver disease, and drug abuse history were excluded as were patients with a prior cystoscopy procedure were excluded. The 60 patients were subclassified randomly according to several pain controlling methods: cystoscopy + intravenous (IV) analgesics (group 1, $\mathrm{n}=20$ ); cystoscopy + midazolam (group 2, $\mathrm{n}=20$ ); and cystoscopy + propofol (group 3, n=20). This study was approved by Institutional review board of Soonchunhyang University Hospital. Trial registration КСТ0001260.

\section{Procedures}

All patients were placed in the dorsolithotomy position in the operation room. The same two urological surgeons (Jae Heon Kim and Yun Seob Song) performed all cystoscopic ureteral stent removals using a 17.5 Fr rigid cystoscope. Prior to the procedure, the urethra was instilled with $2 \%$ lidocaine topical jelly. After 5-10 min, the cystoscope was introduced to the urethra and bladder, and the ureteral stent was removed using foreign body forceps. In the operating room, electrocaridography, noninvasive blood pressure monitoring, and pulse oximetry monitoring were done. Vital signs were checked during the procedure and after the procedure in the day care unit. The presence of complications including oxygen desaturation, autonomic movement, arrythmia, injection pain, and phlebitis were also examined. Before discharge, the patients were asked to rate their comfort level using a visual analog scale (VAS) and satisfaction scale, detailed in the Additional file 1. Recovery from sedation was assessed by the mini-mental state examination (MMSE).

\section{IV administration of ketorolac}

Intravenous analgesic administration was performed after lidocaine jelly instillation into the urethra. Intravenous administration of ketorolac $30 \mathrm{mg}$ was used for pain control. Before discharge, the patients were asked to rate their comfort level as described above.

\section{Moderate sedation with midazolam}

Midazolam with doses of 3-5 mg (no more than $0.03 \mathrm{mg} / \mathrm{kg}$ ) was administrated to the subjects after lidocaine jelly instillation. The status of sedation was measured and divided according to five stages, as described in the Additional file 1. Cystoscopy was started when the stage was over three. After the procedure was finished, the midzolam antidote, flumazenil was administrated.
After the procedure, the patient was transferred to day care unit and was discharged when they displayed normal orientation of time and space with vital signs within the normal range.

\section{Deep sedation with propofol}

Patients received an injection of $0.2 \mathrm{mg}$ glycopyrollate about $20 \mathrm{~min}$ before induction of deep sedation. Sedation was induced with propofol $2 \mathrm{mg} / \mathrm{kg}$ without muscle relaxation and was maintained using propofol $10 \mathrm{mg} / \mathrm{kg} / \mathrm{h}$. After induction, the anesthesiologist applied a face mask and assisted with ventilation with $100 \% \mathrm{O}_{2}$. After the procedure, the patient was transferred to day care unit and was discharged when they displayed normal orientation of time and space with vital signs within the normal range.

\section{Cost calculation}

Cost was described as medical insurance fee and real patient expense. In Korea, due to National Medical Insurance system, a patient may pay $20-100 \%$ of total medical insurance fee. Rate of exchange between Korea Won and the US dollar was 1120.6 won for 1 dollar.

\section{Treatment satisfaction}

The treatment satisfaction questionnaire included five subscales: "very satisfied", "satisfied", "average", "not satisfied", and "totally not satisfied". These subscales were divided into two groups: "Satisfactory" included "very satisfied" and "satisfied", and "Not satisfactory" included "average", "not satisfied", and "totally not satisfied".

\section{Questionnaire about seeking another method}

After the procedure, a questionnaire solicited responses about seeking other pain controlling method. The question asked was "Do you prefer another pain controlling method if it were effective although you could pay more?"

\section{Statistical analyses}

Data were analyzed using SAS version 9.1 (SAS Institute, Cary, NC, USA). The Kolmogorov-Smirnov test was used to verify the normality of distribution of continuous variables. Nonparametric tests of comparison were used for variables evaluated as not normally distributed. Median and minimal to maximal range were used as appropriate to describe statistics. Difference testing between groups was performed using Kruskal-Wallis test and Mann-Whitney test as appropriate.

\section{Results}

There was no significant difference among blood pressure, pulse rate, $\mathrm{O} 2$ saturation during the procedure including those 3 different methods. The differences of pre-operative and post-operative MMSEs including pre- 
Table 1 Satisfaction and pain scores among the three groups

\begin{tabular}{lllll}
\hline & Group 1 & Group 2 & Group 3 & P value \\
\hline Age & $49.50(26-70)$ & $47.50(15-70)$ & $49.50(29-72)$ & 0.731 \\
BMI & $26.5(19.8-31.2)$ & $25.6(21.4-28.3)$ & $26.0(22.6-29.4)$ & $50.4(45.3-75.4)$ \\
Time duration (min) & $11.3(8.6-30.5)$ & $32.6(29.6-40.5)$ & $2.2(1.0-3.2)$ & 0.361 \\
Duaration of procedure (min) & $2.3(1.5-3.3)$ & $2.4(1.3-3.4)$ & $0.00(0-1)^{*, \neq}$ & 0.243 \\
VAS & $8.00(6-10)^{*,+}$ & $5.00(1-7)^{+, \neq}$ & $3(4-5)^{*, \neq}$, & $>0.001$ \\
Satisfaction & $1(0-3)^{*,+}$ & $5(6-9)^{*, \neq}$ & $<0.001$ \\
Willing to undergo the procedure (VAS) & $2(0-4)^{*,+}$ & $5(4-8)^{+, \neq}$ & $<0.001$ \\
\hline
\end{tabular}

Group 1, Cystoscopy + IV analgesics, Group 2, Cystoscopy + midazolam, Group 3, Cystoscopy + propofol, BMI Body mass index, VAS Visual analog pain scale.

Time duration procuedural time + recovery time.

Data are expressed as median number with minimum to maximum number.

$P$ values were analyzed by Kruskal-Wallis test.

${ }^{*},+, \neq$ :significant differences by Post hoc analysis.

operative and post-operative were not noted among the three groups. The time duration including procedural time and recovery time showed longer in group 2 and 3 than group1 (Table 1).

Group 1 experienced more pain and more dissatisfaction with the procedure than group 2 and group 3. VAS of group 1 was higher than that of group 2 and group 3 $(\mathrm{P}<0.001)$ (Table 1). Satisfaction scale of group 1 was lower than that of group 2 and group 3 ( $\mathrm{P}<0.001)$ (Table 1). Comparison of group 2 and 3 revealed lower VAS in group $3(\mathrm{P}<0.001)$ and higher satisfaction rate in group $3(\mathrm{P}<0.001)$ (Figures 1 and 2$)$.
Total medical insurance fee for group 1, 2, and 3 was US102.63, US108.65, and US218.47, respectively (Table 2). For real patient expense, the cost in the same respective order was US57.94, US61.55, and US119.98 (Table 2). Detailed expenses are provided in Table 2.

Comparison of groups 2 and 3 revealed less pain and higher satisfaction rate in group 3 ( $\mathrm{P}<0.001$ for both). In group1, 17 (85\%) patients wanted other treatment modalities, whereas in eight of group 2 patients $(40 \%)$ and no group 3 patients wanted other treatment modalities. Group 1 revealed lower VAS score of willing to undergo the procedure again than group 2 and group $3(<0.001)$.

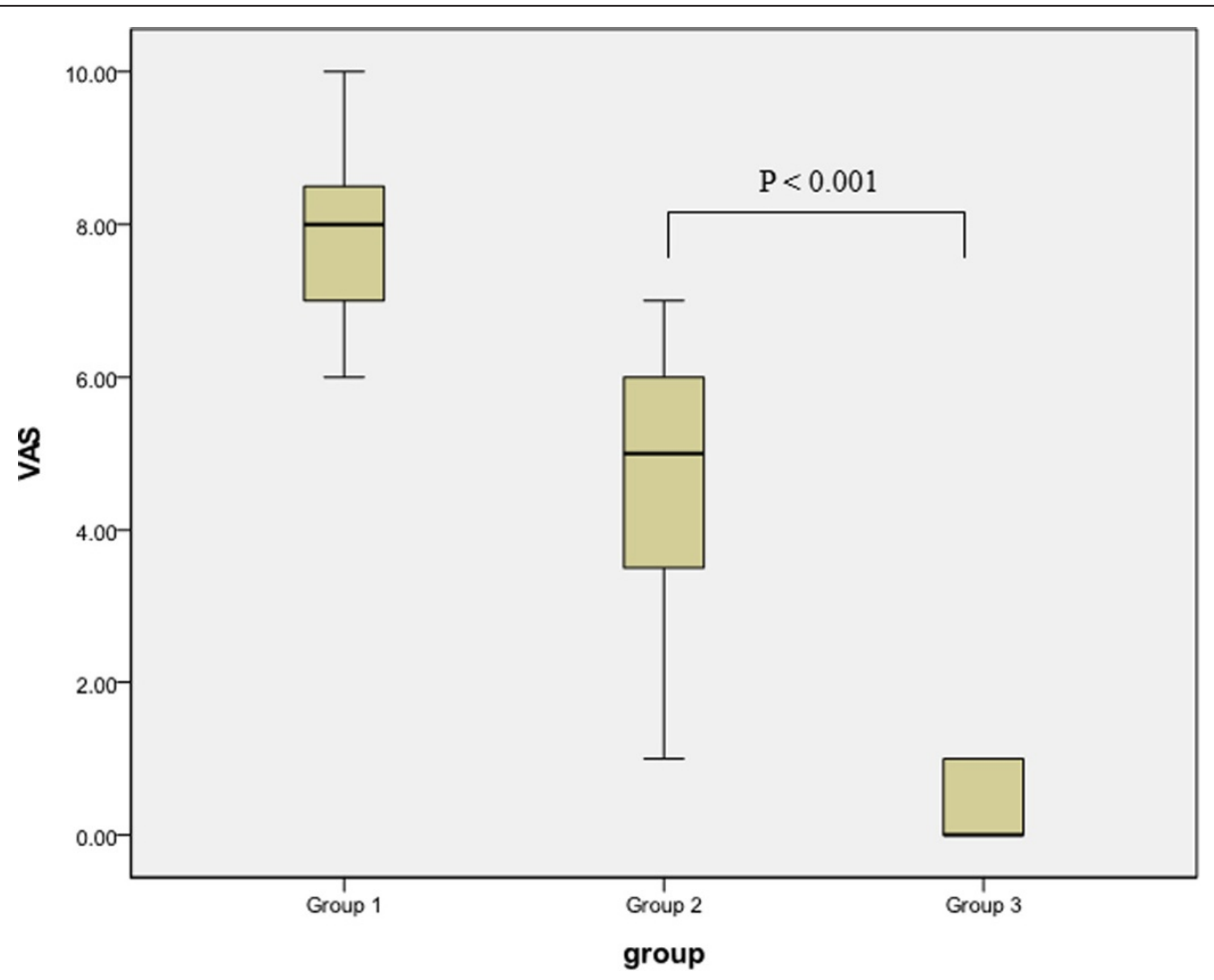

Figure 1 Comparison of VAS among group 1 (cystoscopy + IV analgesics), group 2 (cystoscopy + midazolam), and group 3 (cystoscopy + general anesthesia using propofol). 


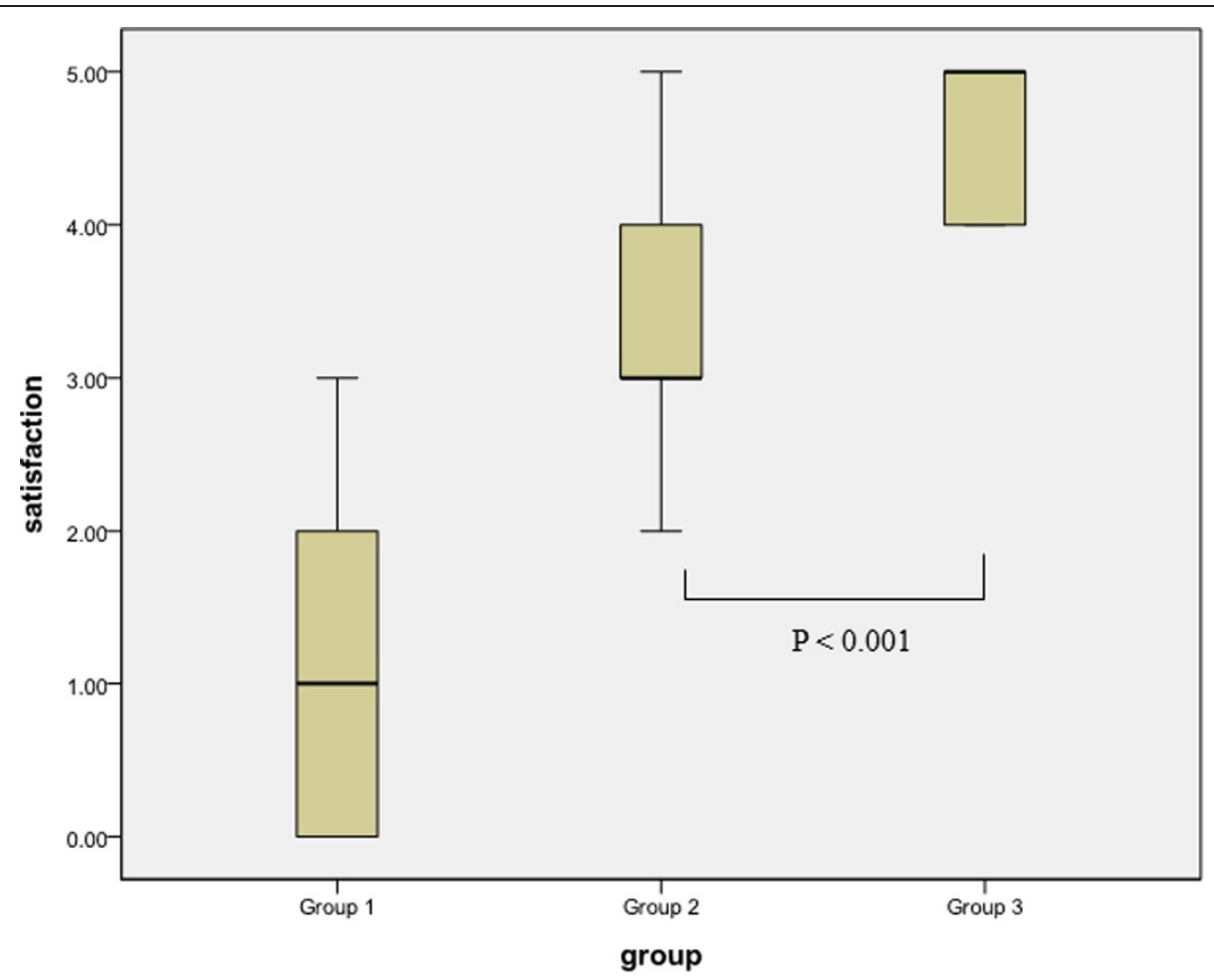

Figure 2 Comparison of satisfaction among group 1 (cystoscopy + IV analgesics), group 2 (cystoscopy + midazolam), and group 3 (cystoscopy + general anesthesia using propofol.

Table 2 Cost expenses among the three groups

\begin{tabular}{|c|c|c|c|c|c|c|}
\hline & \multicolumn{2}{|l|}{ Group 1} & \multicolumn{2}{|l|}{ Group 2} & \multicolumn{2}{|l|}{ Group 3} \\
\hline & Cost (won) & Patient expense (won) & Cost (won) & Patient expense (won) & Cost (won) & Patient expense (won) \\
\hline Fee for procedure & 75,647 & 45,388 & 75,647 & 45,388 & 75,647 & 45,388 \\
\hline Consultation fee & 13,090 & 13,090 & 13,090 & 13,090 & 13,090 & 13,090 \\
\hline Normal saline $1 \mathrm{~L}$ & 1,099 & 659 & 1,099 & 659 & 1,099 & 659 \\
\hline Intravenous injection fee & 3,315 & 663 & 3,315 & 663 & 6,630 & 1,326 \\
\hline Day care unit & & & & & 38000 & 38000 \\
\hline Aneshesia fee & & & & & 92,950 & 18,590 \\
\hline Profopol & & & & & 17,398 & 17,398 \\
\hline Midazolam & & & 761 & 456 & & \\
\hline Flumazenil & & & 7,868 & 4,720 & & \\
\hline IV NSAIDs & 1,889 & 1,134 & & & & \\
\hline Blood O2 saturation monitoring & 5,490 & 1,098 & 5,490 & 1,098 & & \\
\hline ECG monitoring & 6,460 & 1,292 & 6,460 & 1,292 & & \\
\hline Blood pressure monitoring & 8,020 & 1,604 & 8,020 & 1,604 & & \\
\hline Total costs (won) & 115,010 & 64,928 & 121,750 & 68970 & 244,814 & 134,451 \\
\hline Total costs (US dollar) & 102.63 & 57.94 & 108.65 & 61.55 & 218.47 & 119.98 \\
\hline
\end{tabular}

Gourp 1 Cystoscopy + IV analgesics, Group 2 Cystoscopy + midazolam, Group 3 Cystoscopy + propofol, ECG electrocardiography, NSAIDS non-steroidal anti-inflammatory drugs. 
Group 2 showed also lower VAS score of willing to undergo the procedure again than group $3(<0.001)$ (Table 1).

\section{Discussion}

Cystscopy is the standard technique used to removal or exchange a ureteral stent. In addition to the large diameter of cystoscopies, which can induce pain, several conditions make this technique more difficult, especially in male patients, due to the longer urethra and prostatic enlargement.

Several retrograde methods without conventional cystoscopy have been developed [7-10]. Successful outcomes have been reported using retrograde ureteral stent removal or change under fluoroscopic guidance, but most patients in these studies were female, and only one study included male patients [10].

Ureteroscopy is one of the most common methods to treat urinary stones [11]. In many cases, ureteral stent insertion follows ureteroscopy [1]. Although cystoscopic ureteral stent removal is common, discomfort associated with the procedure is unclear. Our study is the first clinical trial to address this issue.

Local anesthesia has long been used in men undergoing rigid cystoscopy. Recent reports indicated that lidocaine gel has no effect on pain during cystoscopy [7-11]. The diverse efficacy of lidocaine gel may be because the absorption of topical lidocaine is slow and incomplete. Several groups have demonstrated that maximal lidocaine absorption requires 15 to 60 minutes [5,12].

To overcome this limited effect of lidocaine jelly, several methods have been introduced such as sleep induction using midazolam, pain killers, or listening to music $[4,6,13]$. Midazolam is a well-known sedative drug with amnesic properties. Previous studies have demonstrated that midazolam can yield anterograde amnesia without retrograde amnesia [14-17]. Midazolam produces the immediate onset of anterograde amnesia in patients, which could be useful in forgetting the painful events [14].

One of the prominent features of our study was that, for the first time, we adapted a propofol in cystoscopy or cysoscopic ureteral stent removal. Propofol is safe and effective during gastrointestinal endoscopy procedures $[18,19]$. Moreover, it has been associated with shorter recovery time, better sedation, and lack of a harmful effect on cardiopulmonary function. Our study showed that both the group with midazolam and propofol showed longer time duration but the differences were not large. Considering the nature of pilot study to use propofol, we had assistance of anesthetic department for safety. In the future, the procedures using propofol might be feasible in outpatient department.

In this study, the satisfaction was the greatest in the group with using propofol. Cystoscopic procedure with IV pain killers was not effective at all. Procedures using midazolam yielded less pain and greater satisfaction than procedures with IV pain relievers. Patients treated with propofol reported the greatest satisfaction despite spending additional recovery time in the day care unit.

Moreover, the gap of real expense among the three groups was not large. This is might be due to a unique medical insurance system in Korea. The gap difference of cost should be validated in other countries with different medical systems.

The present study has several limitations. We did not assess the pain felt by patients during each step of the procedure. Moreover, the sample size was relatively small, and the study was not blinded for patients and physicians, which could result in some bias in data interpretation or reporting of satisfaction and pain levels. Second, the sample size was relatively small but owing to its nature of pilot study, the differences of main outcomes among each groups were definite.

\section{Conclusions}

Urologists have to pay more concern to cystscopic ureteral stent removal. With the traditional methods of lidocaine jelly and pain killers, patients have to suffer from pain and discomfort. Midazolam and propofol could be a options to control both. Considering the safety and the high prevalence of use of midazolam and propofol, urologists should not hesitate to adapt new methods in pain control during cystoscopic ureteral stent removal.

\section{Additional file}

Additional file 1: Mini-mental state examination.

\section{Competing interests}

The authors declare that they have no competing interests.

\section{Authors' contributions}

JHK and YSS contributed with the conception and design of the study and drafted the manuscript, JHK, YSS, HC, DS, SWC, MKL, and SYP collected data and performed the analyses. All authors read and approved the final manuscript.

\section{Acknowledgement}

This work was supported by Soonchunhyang Univeristy Research Fund.

\section{Author details}

'Department of Urology, Soonchunhyang University Hospital, 657 Hannam-Dong, Yongsan-Gu, Seoul 140-743, Korea. ${ }^{2}$ Department of Anesthesiology and Pain Medicine, Soonchunhyang University Hospital, Seoul, Korea. ${ }^{3}$ Department of Urology, Korea University Hospital, Ansan, Korea. ${ }^{4}$ Department of Surgery, Soonchunhyang University Hospital, Seoul, Korea.

Received: 16 March 2014 Accepted: 23 October 2014 Published: 18 November 2014

\section{References}

1. Tang L, Gao X, Xu B, Hou J, Zhang Z, Xu C, Wang L, Sun Y: Placement of ureteral stent after uncomplicated ureteroscopy: do we really need it? Urology 2011, 78:1248-1256. 
2. Wetton CW, Gedroyc WM: Retrograde radiologic retrieval and replacement of double-J ureteric stents. Clin Radiol 1995, 50:562-565.

3. Park SW, Cha IH, Hong SJ, Yi JG, Jeon HJ, Park JH, Park SJ: Fluoroscopy guided transurethral removal and exchange of ureteral stents in female patients: technical notes. J Vasc Interv Radiol 2007, 18:251-256.

4. Demir E, Kilciler M, Bedir S, Erken U: Patient tolerance during cystoscopy: a randomized study comparing lidocaine hydrochloride gel and dimethyl sulfoxide with lidocaine. J Endourol 2008, 22:1027-1029.

5. Axelsson K, Jozwiak H, Lingårdh G, Schönebeck J, Widman B: Blood concentration of lignocaine after application of $2 \%$ lignocaine gel in the urethra. Br J Urol 1983, 55:64-68.

6. Song YS, Song ES, Kim KJ, Park YH, Ku JH: Midazolam anesthesia during rigid and flexible cystoscopy. Urol Res 2007, 35:139-142.

7. Birch BR, Ratan P, Morley R, Cumming J, Smart CJ, Jenkins JD: Flexible cystoscopy in men: is topical anaesthesia with lignocaine gel worthwhile? Br J Urol 1994, 73:155-159.

8. McFarlane N, Denstedt J, Ganapathy S, Razvi H: Randomized trial of $10 \mathrm{~mL}$ and $20 \mathrm{~mL}$ of $2 \%$ intraurethral lidocaine gel and placebo in men undergoing flexible cystoscopy. J Endourol 2001, 15:541-544.

9. Stein M, Lubetkin D, Taub HC, Skinner WK, Haberman J, Kreutzer ER: The effects of intraurethral lidocaine anesthetic and patient anxiety on pain perception during cystoscopy. J Urol 1994, 151:1518-1521.

10. Chen YT, Hsiao PJ, Wong WY, Wang CC, Yang SS, Hsieh CH: Randomized double-blind comparison of lidocaine gel and plain lubricating gel in relieving pain during flexible cystoscopy. J Endourol 2005, 19:163-166.

11. Kobayashi T, Nishizawa K, Mitsumori K, Ogura K: Instillation of anesthetic gel is no longer necessary in the era of flexible cystoscopy: a crossover study. J Endourol 2004, 18:483-486.

12. Ouellette RD, Blute R Sr, Jaffee S, Bahde C: Plasma concentration of lidocaine resulting from instillation of lidocaine jelly into genitourinary tract prior to cystoscopy. Urology 1985, 25:490-495.

13. Yeo JK, Cho DY, Oh MM, Park SS, Park MG: Listening to music during cystoscopy decreases anxiety, pain, and dissatisfaction in patients: a pilot randomized controlled trial. J Endourol 2013, 27:459-462.

14. Dundee JW, Wilson DB: Amnesic action of midazolam. Anaesthesia 1980, 35:459-461.

15. Koht A, Moss Jl: Does midazolam cause retrograde amnesia, and can Xumazenil reverse that amnesia? Anesth Analg 1997, 85:211-212.

16. Twersky RS, Hartung J, Berger BJ, McClain J, Beaton C: Midazolam enhances anterograde but not retrograde amnesia in pediatric patients. Anesthesiology 1993, 78:51-55.

17. Bulach R, Myles PS, Russnak M: Double-blind randomized controlled trial to determine extent of amnesia with midazolam given immediately before general anaesthesia. Br J Anaesth 2005, 94:300-305.

18. Qadeer MA, Vargo JJ, Khandwala F, Lopez R, Zuccaro G: Propofol versus traditional sedative agents for gastrointestinal endoscopy: a meta-analysis. Clin Gastroenterol Hepatol 2005, 11:1049-1056.

19. Bo LL, Bai Y, Bian JJ, Wen PS, Li JB, Deng XM: Propofol vs traditional sedative agents for endoscopic retrograde cholangiopancreatography: a meta-analysis. World J Gastroenterol 2011, 17:3538-3543.

doi:10.1186/1471-2490-14-90

Cite this article as: Kim et al.: Pain and satisfaction during rigid cystoscopic ureteral stent removal: a preliminary study. BMC Urology 2014 14:90.

\section{Submit your next manuscript to BioMed Central and take full advantage of:}

- Convenient online submission

- Thorough peer review

- No space constraints or color figure charges

- Immediate publication on acceptance

- Inclusion in PubMed, CAS, Scopus and Google Scholar

- Research which is freely available for redistribution 